\title{
The Analysis on the Influence of Network Literature on the Phenomenon of Youth Cultural from the Perspective of Cultural Psychology
}

\author{
Yali Teng \\ Huanghe Science and Technology College \\ Zhengzhou, China
}

\begin{abstract}
As a free and independent space, the network has become an effective way for many young people to release their feelings and anxiety. Naturally, the network literature formed has become the direct reflection of self consciousness and social psychology of the young in current China. Young people complete the control of the real world to accomplish pressure relief, life experience, life meaning, and even escape from and resistance against the world through the network writing or reading. Therefore, this thesis tries to elaborate the influence of network literature on youth culture from the perspective of culture psychology.
\end{abstract}

Keywords-culture psychology; analysis; network literature; youth culture

\section{INTRODUCTION}

As a kind of psychological mechanism, network literature activity is the reflection of real and psychological reality and real experience of the youth of the day. It shows the cultural psychology with the nature of "compensation" and "transplant" , and the individualistic value orientation, as well as the self-awareness of self-ego.

\section{The CUltural PSYCHOLOGY OF COMPENSATION AND EMPATHY}

In psychology, "psychological compensation" refers to try to replace the original targets with new ones and taste the pains of original failure with present success, when personal goals cannot be achieved due to subjective or objective obstacles. In the real life, the dreams cannot be achieved should be compensated by means of art, and the essence of compensation is to explore the potential of a person or strengthen his power to balance his weaknesses. In the fantasy works, ordinary heroes easily achieve the perfect life, and enjoy high status, power, beauty, courage and wealth in a short time through his struggle and control of a magical opportunity. "Xiang Shaolong" in A Step into the Past, "Zhang Xiaofan and Lin Jingyu" in Jade Dynasty, "Han Li" in Fanrenpc all of them are considered to be ordinary people with various shortcomings. With the help of talents and opportunities, they become well-known heroes from ordinary men in the fantasy world. The highlights of the experience of the protagonist's life in the novel, not only to meet the writer's fantasy to success to a certain extent, but is very easy to get approvals of readers, which is called psychological compensation. In online writing, the novels whether based on fantasy series written by male writers, or time-travel series created by females, are not the shadow of the real world but the inner mirror of human.

With the imagination of the writer's subjective consciousness, they build a world model symbolizing world view and dreams. At the same time, the bold imagination and ideas in this text meet the readers' expectation and pleasure, satisfy people's desire of imagination, and make them temporarily forget social hardship, survival pressure and many unsatisfactory things in the reality while reading. This is a kind of literary reception in the process of emotional "shift", namely "empathy" and "implication". Readers put all of their emotions even themselves into the protagonists that are similar to themselves through reading to get an emotional abreaction or compensation; these are also the important reasons that current time-travel TV series and the novels based on the plots are flourishing. Such as "Ming Qingwei", the heroine in "Dream to Qing Dynasty", having a good appearance, good family, she gives a deep impression to all the sons of Kangxi emperor with her modern female's characteristics of unique personality and make all of them fall in love with her.

The desire to be recognized, to succeed, and to be loved in the value of the existence of individuals are difficult to be fully reflected in the modern society. However, the protagonists going through into the ancient environment or another world in the novel, have the knowledge and ability to do anything beyond their social demands and the understanding of the historical process. Rich or noble, the protagonists in the novels will have a romantic relationship with a certain people in that time to give readers a feeling of love and miracle. This not only satisfies the writer's own psychological compensation for love and personal value, but also satisfies the readers'.

Therefore, the network literature writing and reading activities are the external forms of youth psychological compensation and emotional empathy, and it helps relieve stress through a variety of text activities, as well as meet their demands of "superego" to reach the balance of personality and psychological health. 


\section{THE "SELF CONSCIOUSNESS" OF SUPEREGO}

In Freud's theory, "superego" is the highest part of personality structure as well as a kind of perfection of "self" ideal. To build the brand of female reading "the century of happy reading" when recruiting writers on campus, some enterprises advertise with the slogan of "every girl is a writer as long as you have a princess dream". It fits poetically and teases dreamy color of the hearts of contemporary females. The chief actors in series of senior cadres and rich family in Urban love stories are often handsome, wealthy, arrogant and gentle. They are born with a golden key, obsessed by and indulged in thousands of beauties. However, when meeting attractive females such as beautiful and gentle, intellectual, lively or quiet and pleasant women, they become very spoony and will never change their hearts until death. All these are full of the coverage of superego of "writers and readers", especially for female readers, when reading such novels online, they are easy to produce the perfect personality transposition ideas, and the perfect loves created by words are easy to take them into the perfect world that they look forward to. Some time-travel novels such as" step by step" reflect the emphasis on females from the characters to the structure of the story through the novel; the stories derive women from their attempts to solve the unavoidable anxiety in reality and also highlights "superego" in subconscious.

While for male writers and readers, the individualism in fantasy is undoubtedly the best interpretation of "superego". All males whether will take or have taken the burden of the family, are unable to avoid the pressure of work and life. So how to find a way to relieve the pressure is a difficult problem that modern men have to solve. They hope that one day they will become invincible with soft beauties around, while all these can only be met in the fantasy network novels.

Therefore, in the Internet era full of uproar and fury, fickleness and desire, the network text projected the emotions and feelings of life in specific sectors of youth, and they get rid of the political, moral and realistic shackles with the help of this platform. At this point, both authors and readers are trying to release the desire, no imprisonment of rules, they are willing to use texts or reading to conjecture the hidden "superego". It can be said that the network novel offers a new channel of watching and expressing the world. The writing and expression, reading and acceptance of young people are not only the general enjoyment in the meaning of texts and culture; it reflects the cultural psychology and value pursuit of the young people in current era.

\section{ThE VALUE ORIENTATION OF INDIVIDUALISM}

Values are the core of culture, and people's values are related to a certain cultural background. In the 1950s, young people pursue "to live like Paul", and in the 1960s, the young believes that "people should live like Lei Feng; while in contemporary society, it is very difficult to see the spirits of heroic dedication in the young generation. The young broke the shackles of the inherent ideological and cultural psychological model, began to think independently and compare to establish new value concepts and standards, and took free and individual development as their main goal of life. What's more, their value orientation is bulit more on personal autonomy and interests.

They believe that people are the creatures that need to meet the immediate material interests firstly. In the pursuit of power and money, more and more young people show their indifference on politics and exclusion on metaphysical problems. Compared to the generation of their fathers, the value standard of contemporary youth in China lacks idealism and transcendence but increases utilitarian and secularity. In multi-culture, the choices of life values in the young and middle class are diversified and individualistic, and they have different values and value orientations, which are more tolerant than before. They think that as long as the behaviors do not violate or infringe social and others' interests, they are allowable and should be treated with tolerance. Therefore, their choices of value show the characteristics of more tolerant attitude towards different value orientation manifesting their increasing self-awareness, personal standard of value pursuit, a strong utilitarian value standard.

Network novels rarely portray characters, but put emphasis on the construction of plots. Even so, the development of a single story makes the behaviors of the characters show a clear tendency to one's own interests. For example, the protagonist Li Qiang, a character in the first book of Chinese fantasy novels-Xenjo Online, just a shrewd businessman firstly, became a supernatural being for an opportunity after killing his wife's lover accidentally and ran away. Faced with powerful enemies, Li Qiang's first thought is "to escape". "the first rule of doing things of Han $\mathrm{Li}$ in "Fanrenpc" is "interest". He works only for interests, but he does not encroach these of others. In these novels, everyone contains his individual position of self-interests whether it is the ordinary people with money, the spiritual Gods, or a variety of demons and monsters. Whether seeking domination in the world or struggling in workplaces, what these novels reflect are the desire to money, beauties, and powers of young people in current society as well as the need to be appreciated by others. All of them are self-oriented, trying to surpass others, and fully follow their own selfconsciousness. This situation has reflected the decreasing values of the young in our contemporary cultural environment. For example, in "stars change" of the reflected works of "I eat tomatoes", if the hero in the novel was replaced to be a "after 80 and 90" young man living in the real society, the key words will change into negative ones such as loneliness, violence, the pursuit of individual power, without a clear moral and views on right and wrong, being common manifestation of psychological characteristics of the young generation.

The individualism embodied by universal mentality and the characteristics of youth sub culture, is fully guided by self-consciousness. The emphasis on individual subject consciousness, infinite pursuit of individualism, excessive expansion of utilitarian, and going to extremes are the desire for wealth, the worship for power, and the naked infatuation for women. The spontaneous hedonism, directness, and the uncontrolled and self-centered emotional strength advocated by young man, not only make them get into the dilemma of 
losing in the choice of realistic value and the ultimate value but the individualism-oriented guideline to thoughts and action. It contains a great antisocial risk in this fast-paced life of adolescence and rebellious stage.

Daniel Baer in 1970s has expressed the view "the hubris of infinite self spirits is hidden behind the modern people's Millennium theory". The value crisis caused by these lies in: "the modern people's pride lies in refusing to acknowledge the limitations, but sticking to the constant expansion of the modern world: the modern world sets a fate beyond morality for the reality-beyond morality, beyond tragedy, and beyond the culture". Some network literature largely abandons and neglects traditional emotional attitudes based on rationalism, dispel people's pursuit of lofty value of life by entertainment, and express their anxiety by their ridicule and cynical attitudes to life, even escape from the reality in the pursuit of sensory enjoyment and self-stimulation. In advocating the values of violence, homosexuality, hedonism, decadence, individualism and others, the young falling into the abyss of spiritual emptiness. Therefore, the essence of this kind of literary network literature activities is the vulgarization of literature and art in the trend of youth subculture. It also implies resistance and rebellion against the mainstream society. This tendency in the current system is extremely unfavorable for the integration of youth and society, the construction of the environment of mass culture, as well as the spiritual beliefs of young people and the pursuit of the meaning of life.

In the movement of youth subculture, there is a kind of cultural consequence and social influence called "zero structure". "Zero structure" as the name implies is the indifferent structure transferring traditional value into nothing, thus subverting all established social boundaries and removing all cultural barriers. Speaking positively, "zero structure" means the abolition of all boundaries, breaking all kinds of taboos and rules, and it shows a free and unfettered life ideal best. Speaking negatively, it is a kind of abnormal social state, which is full of dangerous and may eventually lead the society into a dilemma. "Zero structure" abolishes all prohibitions and makes social activities in disorder, which is a Kingdom of widespread deviance and the prevalence of crime, but also a deep abyss to be launched. "Infinity is a bud of redemption for the pursuit of the impossible things is the inevitability goal of mankind, while any attempt to live entirely in an alternative world is tantamount to going mad." The values and world order advocated by the contemporary Chinese youth in the network works are many "zero structures "The ideal and sustainable world that they build can make the social contact of young generation becomes indifferent and superficial with direct appeal and sensual temptation, makes social contact increasingly fragile because of the virtualization, and social responsibility become loose or even not exist in the manipulation of exchange, business, and market. Therefore, only by analyzing deeply how the virtual world changes the way of thinking and behaviors of the young generation, as well as the essence of their deconstruction and subversion of desire while lacking faith, can we find a solution to draw the boundaries between real life and virtual culture in the subconscious, and to make them bear the responsibilities and requirements of the reality while accepting the behaviors of subculture in the young generation. So that the youth are equipped with the awareness of individual autonomy and behavior norms, construct a positive significance of youth subculture activities in order to achieve self education and self growth while showing their infinite spirits of creativity.

\section{CONCLUSION}

Online literatures exist in a diversity of spaces, showing different souls and mentalities, individual lives and social scenes, which to some degree attract the eyeballs of young people who may experience a unique life via reading. As a main carrier of literatures developing rapidly, online literatures have accumulated a great number of readers, however, such works are a reflection of social and cultural psychologies in a certain period; besides, it shall be seen that online literatures may highlight social contradictions rapidly and directly, showing the trend of social and cultural values in the stage. Therefore, to analyze and discuss the social and cultural psychologies based on which online literatures are created will play an active role in digging and getting the value that it should own as a popular literature phenomenon so as to well grasp it as a whole.

\section{REFERENCES}

[1] Cai Zhaohui, Research on the Meaning of Youth Subculture in Network Literature, Seeker, 2007 (11) .

[2] Pei Yucheng, Network Literature: Self-Discipline and Heteronomy, Journal of Hubei Institute for Nationalities (Philosophy and Social Sciences) 2001 (3) .

[3] Tan Dejing, Network Literary Criticism, Beijing: China Federation of Literary and Art Circles Publishing House, 2004. 